\title{
BMJ Open Premenstrual syndrome and alcohol consumption: a systematic review and meta-analysis
}

\author{
María del Mar Fernández,, ${ }^{1,2}$ Jurgita Saulyte, ${ }^{1,2}$ Hazel M Inskip, ${ }^{3,4}$ Bahi Takkouche ${ }^{1,2}$
}

To cite: Fernández MdM, Saulyte J, Inskip HM, et al. Premenstrual syndrome and alcohol consumption: a systematic review and meta-analysis. BMJ Open 2018;8:e019490. doi:10.1136/ bmjopen-2017-019490

- Prepublication history and additional material for this paper are available online. To view these files, please visit the journal online (http://dx.doi org/10.1136/bmjopen-2017019490).

Received 5 September 2017 Revised 13 December 2017 Accepted 9 February 2018

Check for updates

${ }^{1}$ Department of Preventive Medicine, University of Santiago de Compostela, Santiago de Compostela, Spain

${ }^{2}$ Centro de Investigación

Biomédica en Red de Epidemiología y Salud Pública (CIBER-ESP), Madrid, Spain ${ }^{3} \mathrm{MRC}$ Lifecourse Epidemiology Unit, University of Southampton, Southampton, UK

${ }^{4}$ NIHR Southampton Biomedical Research Centre, University of Southampton and University Hospital Southampton NHS Foundation Trust, Southampton, UK

Correspondence to

Dr Bahi Takkouche;

bahi.takkouche@usc.es

\section{ABSTRACT}

Objective Premenstrual syndrome (PMS) is a very common disorder worldwide which carries an important economic burden. We conducted a systematic review and a meta-analysis to assess the role of alcohol in the occurrence of PMS.

Methods We searched MEDLINE, EMBASE, the five regional bibliographic databases of the $\mathrm{WHO}$, the Proceedings database and the Open Access Thesis and Dissertations (OATD) from inception to May 2017. We also reviewed the references of every article retrieved and established personal contact with researchers to trace further publications or reports. We did not include any language limitations. Studies were included if: (1) they presented original data from cohort, case-control or cross-sectional studies, (2) PMS was clearly defined as the outcome of interest, (3) one of the exposure factors was alcohol consumption, (4) they provided estimates of odds ratios, relative risks, or any other effect measure and their confidence intervals, or enough data to calculate them. Results We identified 39 studies of which 19 were eligible. Intake of alcohol was associated with a moderate increase in the risk of PMS (OR=1.45, 95\% Cl: 1.17 to 1.79). Heavy drinking yielded a larger increase in the risk than any drinking $(\mathrm{OR}=1.79,95 \% \mathrm{Cl}: 1.39$ to 2.32$)$.

Discussion Our results suggest that alcohol intake presents a moderate association with PMS risk. Future studies should avoid cross-sectional designs and focus on determining whether there is a threshold of alcohol intake under which the harmful effect on PMS is non-existent.

\section{INTRODUCTION}

Premenstrual syndrome (PMS) consists of a series of recurrent physical and emotional symptoms, including mood swings, tender breasts, food craving, fatigue, irritability and depression, during the luteal phase of the menstrual cycle. ${ }^{12}$ The severity of the syndrome varies from woman to woman and is related to the type and intensity of the symptoms. ${ }^{13}$ While in the United States, the prevalence of the syndrome varies between $20 \%$ and $40 \%$ for cases of moderate severity and between $3 \%$ and $8 \%$ for severe cases, ${ }^{2}$ a recent prevalence meta-analysis shows that the worldwide prevalence sways between $10 \%$ and $98 \%$. $^{4}$

\section{Strengths and limitations of this study}

- This is the first meta-analysis carried out on the relation between alcohol consumption and risk of premenstrual syndrome (PMS), a highly prevalent condition worldwide.

- Exhaustive search of studies was carried out in several bibliographic databases, and unpublished studies were included.

- Intensive sensitivity analyses were performed to assess potential for publication bias and confounding.

- In our subgroup analyses, we were unable to identify any factors that accounted for study heterogeneity.

- In some studies included in this meta-analysis, the assessment of alcohol intake was probably concomitant to the assessment of PMS. A reverse causation process, in which PMS-affected women use alcohol to mitigate the effect of the syndrome, is then plausible.

The economic burden of the syndrome is far from being negligible. For a week every month women affected by this syndrome suffer distress and impairment in interpersonal or workplace functioning. This can lead to at least 2 days per month of absenteeism at work and an increase in medical appointments. ${ }^{25}$ In the US, the cost of the syndrome reaches $\$ 5000$ per case per year. ${ }^{2}$ Each affected woman experiences a total of 3000 days with disabling symptoms during her reproductive life. ${ }^{2}$ The large majority of cases are not diagnosed, either because affected women do not seek medical help or because physicians have difficulties in establishing a firm diagnosis. ${ }^{6}$ Furthermore, premenstrual syndrome was recently found to be a risk factor for hypertension increasing its incidence by $40 \%$.

The WHO warned recently against the increasing alcohol consumption among women related to economic development and changing gender roles, and emphasised the fact that women may be more vulnerable to alcohol-related harm than men. ${ }^{8}$ Several studies have identified an increased burden of PMS among women who consume 
alcohol. ${ }^{9-11}$ However, it is not clear whether this increase in the risk of PMS is due to alcohol consumption or whether alcohol is consumed in an attempt to mitigate the symptoms of the syndrome. ${ }^{12}$ Other studies found that the relation between alcohol and PMS was weak or even non-existent. ${ }^{12-14}$ Furthermore, assessing the role of alcohol in prospective studies is not straightforward. Indeed, it is not feasible to relate alcohol intake to the first occurrence of PMS in the life of a woman, as the first bout of the disease appears at an early age, probably before any alcohol is consumed. Prospective studies aim at determining the role of regular alcohol intake in the occurrence of the next episode of the disease, not the first one.

We are not aware of the existence of any meta-analysis on the topic. We therefore conducted a systematic review of the literature and a meta-analysis to assess the role of alcohol in the occurrence of PMS.

\section{Sources}

To identify all potentially eligible studies, we searched MEDLINE, EMBASE, the five regional bibliographic databases of the WHO (AIM, LILACS, IMEMR, IMSEAR, WPRIM), the Conference Proceedings Citation Index, the Open Access Thesis and Dissertations (OATD), from inception to May 2017.

For Medline, we used the following algorithm both in Medical Subject Heading and in free text words: ("premenstrual syndrome'(MeSH Terms) OR 'premenstrual syndrome'(All Fields)) AND ('ethanol'(MeSH Terms) OR 'ethanol'(All Fields) OR 'alcohol'(All Fields)). An example of this search is given in (online supplementary 1). Similar strategies were used for the other databases.

We also reviewed the references of every article retrieved. Furthermore, we established personal contact with researchers to trace further publications or reports. We did not include any language limitations. All searches were carried out independently by two researchers and results were merged.

\section{Study selection}

Studies were included if: (1) they presented original data from cohort, case-control or cross-sectional studies, (2) PMS or its more severe form, Premenstrual Dysphoric Disorder (PMDD), were clearly defined as the outcome of interest, (3) one of the exposure factors was alcohol consumption, (4) they provided estimates of (OR), rate ratios (RR), or prevalence odds ratios and their confidence intervals, or enough data to calculate them.

If data on the same population were duplicated in more than one publication, the most recent study was included in the analysis.

We developed a standard data-recording form in which we recorded authors, year of publication, study location, study design, sample size, outcome, outcome measurement details, effect estimator (OR, RR, other), effect estimate, $95 \%$ CIs, and adjustment, restriction or matching factors used.
When further clarification was necessary, we attempted to contact the authors. ${ }^{14-16}$

\section{Quality assessment}

Study quality was assessed using a five-point binary scale specifically developed for this study. The scale is based on the Newcastle-Ottawa scale with modifications in view of standard guidelines and our own judgement. ${ }^{17}$ The Newcastle-Ottawa scale is a scoring system that assesses every aspect of an observational epidemiologic study from a methodological point of view. For this meta-analysis, we tried to use those elements that were common to all epidemiological designs and thus shortened the scale considerably. We used the following criteria labelled as ' 1 ' or ' 0 ': (1) Measurement of alcohol intake: through standard or validated questionnaire which includes quantity and/or frequency: 1, else (simple question, no data on frequency or quantity) or not explained: 0; (2) PMS diagnosis: through standard or validated questionnaire: 1, else or not explained: 0; (3) Confounding assessment: results adjusted at least for age and smoking, either in the design phase or in the analysis: 1, else: 0; (4) Participation: participation exceeded $80 \%$ of the people initially approached: 1, else or data not provided: 0; (5) Target population: target population clearly defined: 1 , based on convenience sampling of subjects such as patients of a single consultation or volunteers or not explained: 0

Throughout this assessment, when the information on a specific item was not provided by the authors, we graded this item as ' 0 '. We carried out a pooled analysis on those studies that fulfilled at least three criteria and compared with those that fulfilled fewer than 3. Furthermore, we did not grade cross-sectional studies differently from the case-controls studies in spite of their evident high potential for bias. Our aim was to evaluate design and analysis features that are common to both types of studies. The influence of the design on the pooled estimate was assessed separately from the quality.

Abstracts' review, data extraction and quality scoring were performed independently by two reviewers (J.S and M.F.) and the results were merged by consensus. The complete results for quality scoring are available in (online supplementary 2).

\section{Data synthesis and analysis}

We weighted the study-specific log odds ratios or other ratio measures for case control and cross-sectional studies by the inverse of their variance to compute a pooled estimate. In our search we could not find any cohort studies. For each study, we used the estimate of the effect measure that was adjusted for the largest number of confounders. We present both fixed-effects and random-effects pooled estimates but use the latter when heterogeneity was present. Odds ratios were assumed to be unbiased estimates of the incidence rate ratio. ${ }^{18}$

We calculated odds ratios for any intake of alcohol and for high intake, following the classification given by each individual study. The estimates of studies which failed to 
provide data for different levels of alcohol intake but, instead, assessed alcohol consumption on a yes/no basis, were included in the 'any intake' group.

As no interpretable OR can be computed from them, we excluded those studies the results of which were presented as correlation coefficients between alcohol intake and PMS score. ${ }^{19}{ }^{20}$ When results were presented as standardised differences in means of alcohol intake between cases of PMS and controls, ${ }^{21}{ }^{22}$ they were transformed into odds ratios estimates of exposure on a dichotomous scale (drinkers versus non drinkers). ${ }^{23}$ As drinking patterns vary widely between countries, we calculated the content in ethanol of an average drink using data on consumption of beer, wine and spirits, specific to each country and used different sources to define low, moderate and heavy drinking. ${ }^{8}{ }^{12}$ We considered a consumption of less than $10 \mathrm{~g}$ /day of ethanol as low intake, a consumption between $10 \mathrm{~g}$ /day and the content in ethanol of 1 average drink/day as moderate intake, and a consumption equal or higher than the content in ethanol of 1 average drink/day as heavy intake. To compute an estimate for the category 'any drinking', we pooled the odds ratios obtained in the three categories (low, moderate and heavy intake).

We used the DerSimonian and Laird Q test to check for heterogeneity. To quantify this heterogeneity we calculated the proportion of the total variance due to betweenstudy variance $\left(\mathrm{Ri}\right.$ statistic). ${ }^{24}$ Large values $(>0.75)$ indicate large amount of heterogeneity, values between 0.4 and 0.75 suggest a moderate amount while small values $(<0.4)$ indicate low heterogeneity. We later explored the origin of heterogeneity by restricting the analysis to subgroups of studies defined by study characteristics such as study design, adjustment, origin and quality score. All secondary analyses were planned a priori.

We assessed publication bias, first visually, using funnel plots and then, more formally, using the test proposed by Egger $e t a l .{ }^{25}$ We also used the trim-and-fill method to correct for potential publication bias. All analyses were performed with the software HEpiMA version $2.1 .3^{26}$ and STATA version 12. The transformation of standardised mean differences into odds ratios was performed with the software Comprehensive Meta-Analysis (Englewood, New Jersey, USA).

\section{RESULTS}

We identified 19 studies of 8 different countries that met our inclusion criteria. ${ }^{9-15} 2122$ 27-36

The large majority of the articles retrieved initially were excluded because they did not provide any effect measure. More specifically, we discarded 20 studies (figure 1) for the following reasons: four did not assess PMS cases, ${ }^{1637-39}$ two lacked any control group,${ }^{4041}$ five did not present data on alcohol consumption ${ }^{42-45}$ and one of them did not present a CI, ${ }^{46}$ the full text of one could not be traced, ${ }^{47}$ one was a duplicate publication, ${ }^{48}$ six presented insufficient data to calculate effect measures estimates, ${ }^{19} 20$ 49-52 and one assessed PMS as a risk factor for alcoholism. ${ }^{53}$

For further information we contacted the authors of articles for which the details of the data were not sufficient for effect measures to be computed. We obtained collaboration from three authors. ${ }^{14-16}$ The study by Kiesner et al was finally excluded as its outcome was 'change in PMS score' rather than occurrence of PMS. ${ }^{16}$ Table 1 and figures 2 and 3 present the studies that were finally included in our meta-analysis.

Tables 2 and 3 show that, globally, heterogeneity was substantial overall, and similarly high after stratification by design, quality features, including adjustment for confounders. No individual study seemed to represent an influential point that increased heterogeneity dramatically. We focused on the random effects analyses and presented the fixed effects results for comparison purposes only.

Intake of alcohol was associated with a moderate increase of the risk of PMS (OR=1.45, 95\% CI: 1.17 to 1.79 ), while heavy drinking yielded a larger increase in the risk than any drinking $(\mathrm{OR}=1.79,95 \% \mathrm{CI}: 1.39$ to 2.32). Heavy drinking was associated with a higher risk than any drinking in all subgroup estimates. The pooled estimate of case-control studies was higher than that of cross-sectional studies both for any drinking and heavy drinking. When we restricted our analysis to those studies that presented OR estimates, that is, when we excluded studies that computed standardised mean differences, the pooled estimates were higher: pooled $\mathrm{OR}=1.51 ; 95 \% \mathrm{CI}$ 1.22 to 1.88 for any drinking and $1.90 ; 95 \%$ CI 1.45 to 2.49 for heavy drinking.

The pooled estimate of studies with high quality scores was lower than that from low quality studies.

Except for the criteria 'validated diagnosis' and the criteria 'high response rate' in the any drinking group for which the estimates were similar, when we considered the quality criteria individually instead of just as a global quality score, as recommended by the MOOSE guidelines, ${ }^{54}$ the studies that fulfilled the criteria yielded lower pooled estimates than studies which did not.

About two-thirds of the studies included in this meta-analysis were carried out in US populations. The estimates from American studies were higher than those from other countries, both in the any drinking group and the heavy drinking group.

\section{Publication bias}

The funnel plot (figure 4) for the any drinking group did not suggest asymmetry, a result confirmed by a p-value of the Egger's test of 0.85 . However, the trim-and-fill procedure indicated two potentially missing studies though the corrected random effects pooled $\mathrm{OR}, \mathrm{OR}=1.31$ (95\% CI 1.08 to 1.61 ), was very close to the OR we obtained. Again, the funnel plot for heavy drinking did not suggest any publication bias ( $p$-value Egger's test=0.61) and the trimand-fill method indicated two potentially missing studies and a corrected pooled estimate that was very similar to 


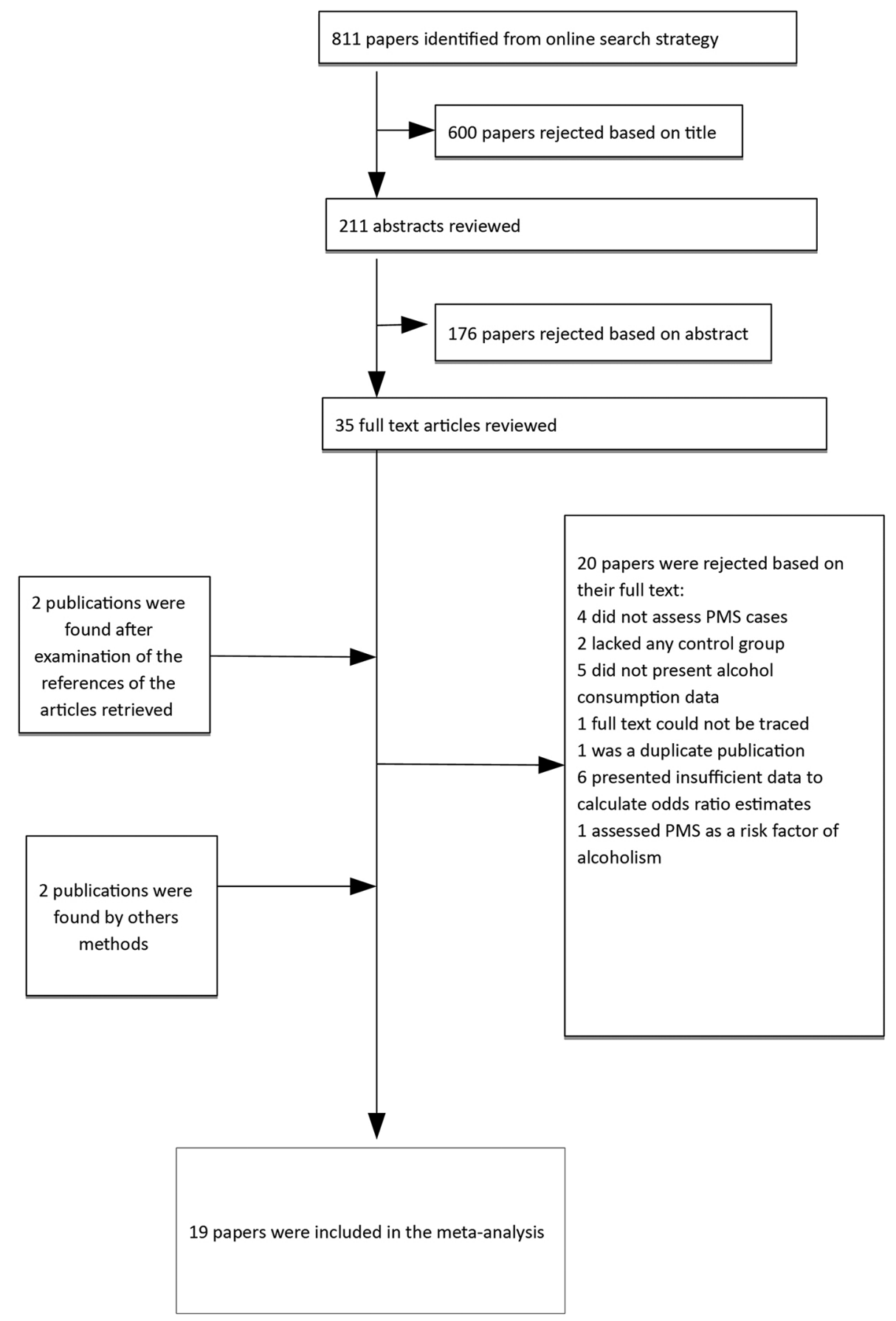

Figure 1 Flow diagram for study selection.

that obtained before correction (random effects pooled $\mathrm{OR}=1.68 ; 95 \% \mathrm{CI}: 1.30$ to 2.16 ).

\section{Sensitivity analysis}

To further evaluate the possibility that our results could be due to publication bias, we assumed that cross-sectional studies represent the design for which publication is least likely if the results were null. We recalculated our pooled estimates under the following extreme assumptions: (1) published cross-sectional studies are only half of the studies of alcohol drinking and PMS ever conducted, (2) all unpublished studies found an OR of 1, (3) the unpublished studies found the same prevalence of PMS as the average of the published studies. Under these extreme assumptions, the random effects pooled estimates still showed a significant increase in risk: OR=1.21 (95\% CI 1.06 to 1.39$)$ for any alcohol drinking and $\mathrm{OR}=1.39(95 \%$ CI 1.15 to 1.69 ) for heavy drinking.

\section{DISCUSSION}

The results of our systematic review and meta-analysis suggest that alcohol drinking is associated with a moderate increase in the risk of PMS. This increase is more pronounced for heavy drinking, which favours a 


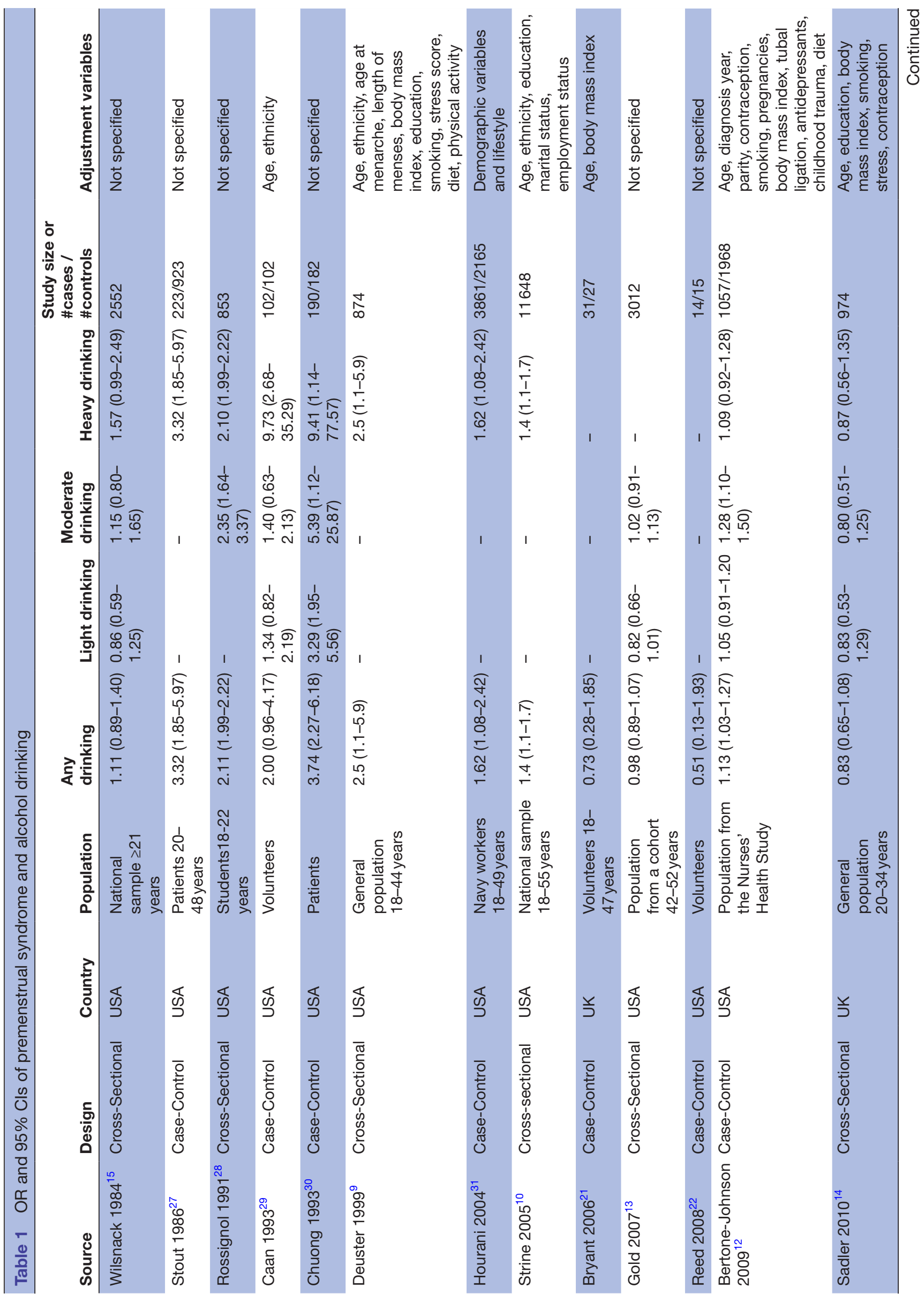

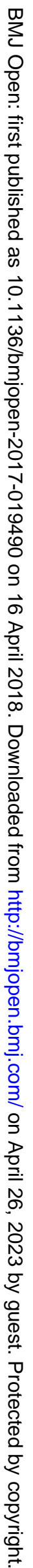




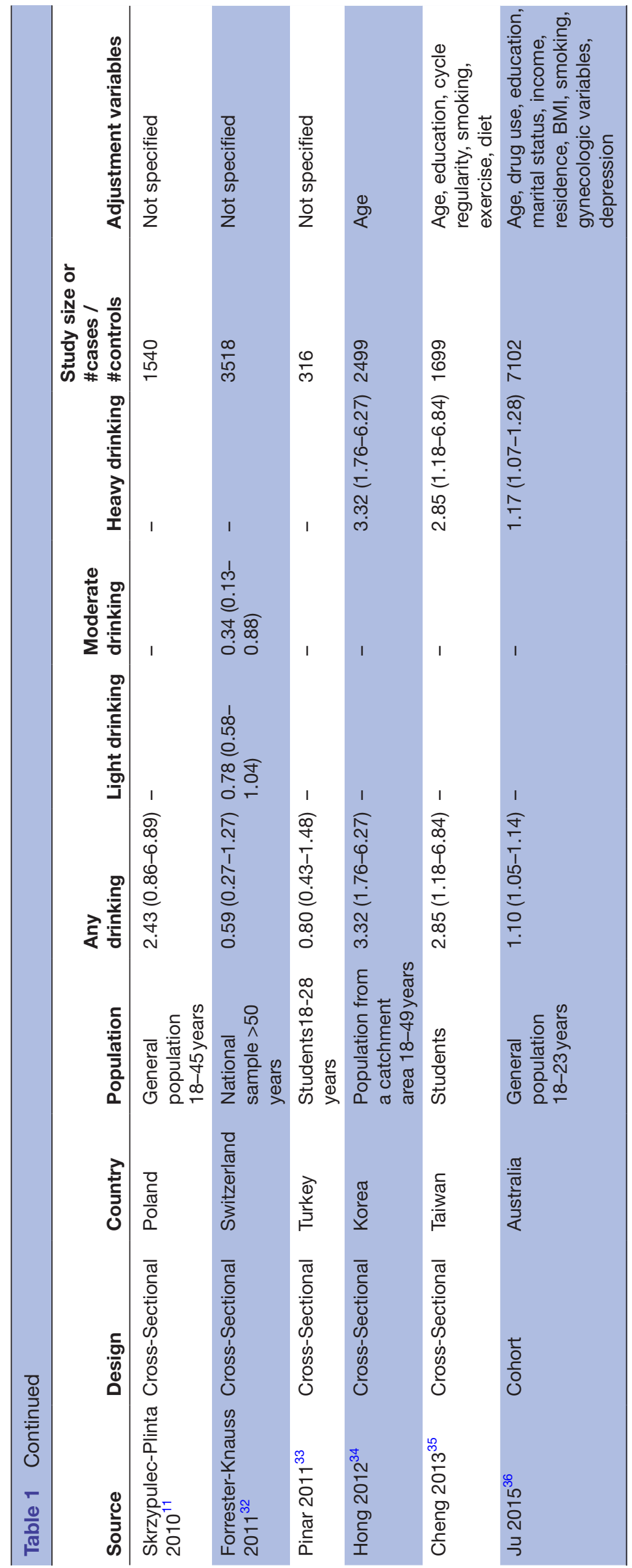

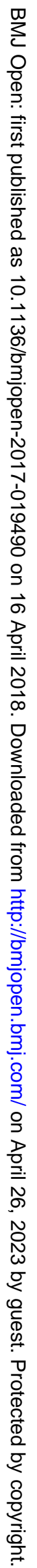




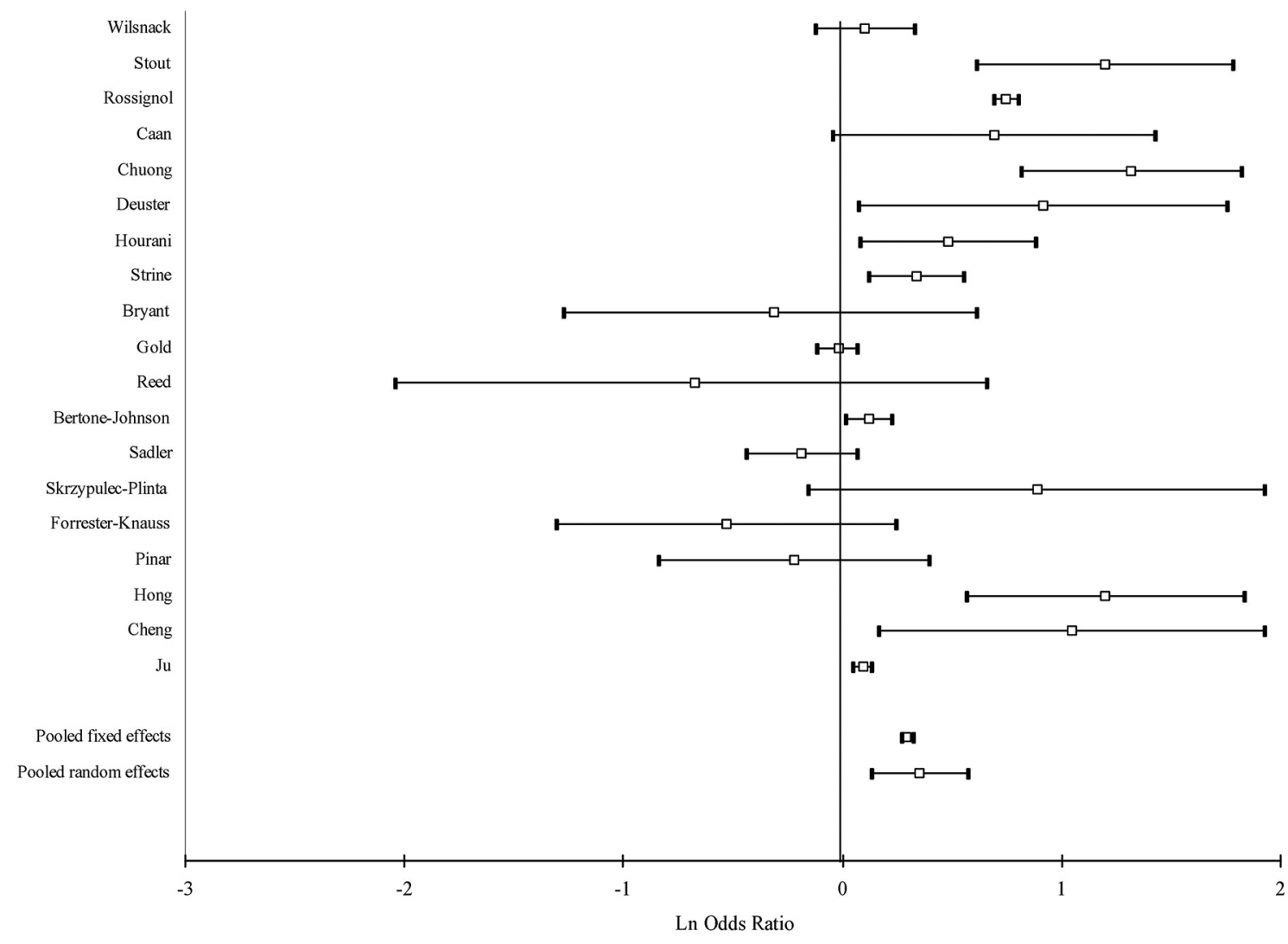

Figure 2 Forest plot of study-specific and pooled OR of alcohol drinking and premenstrual syndrome: any drinking.

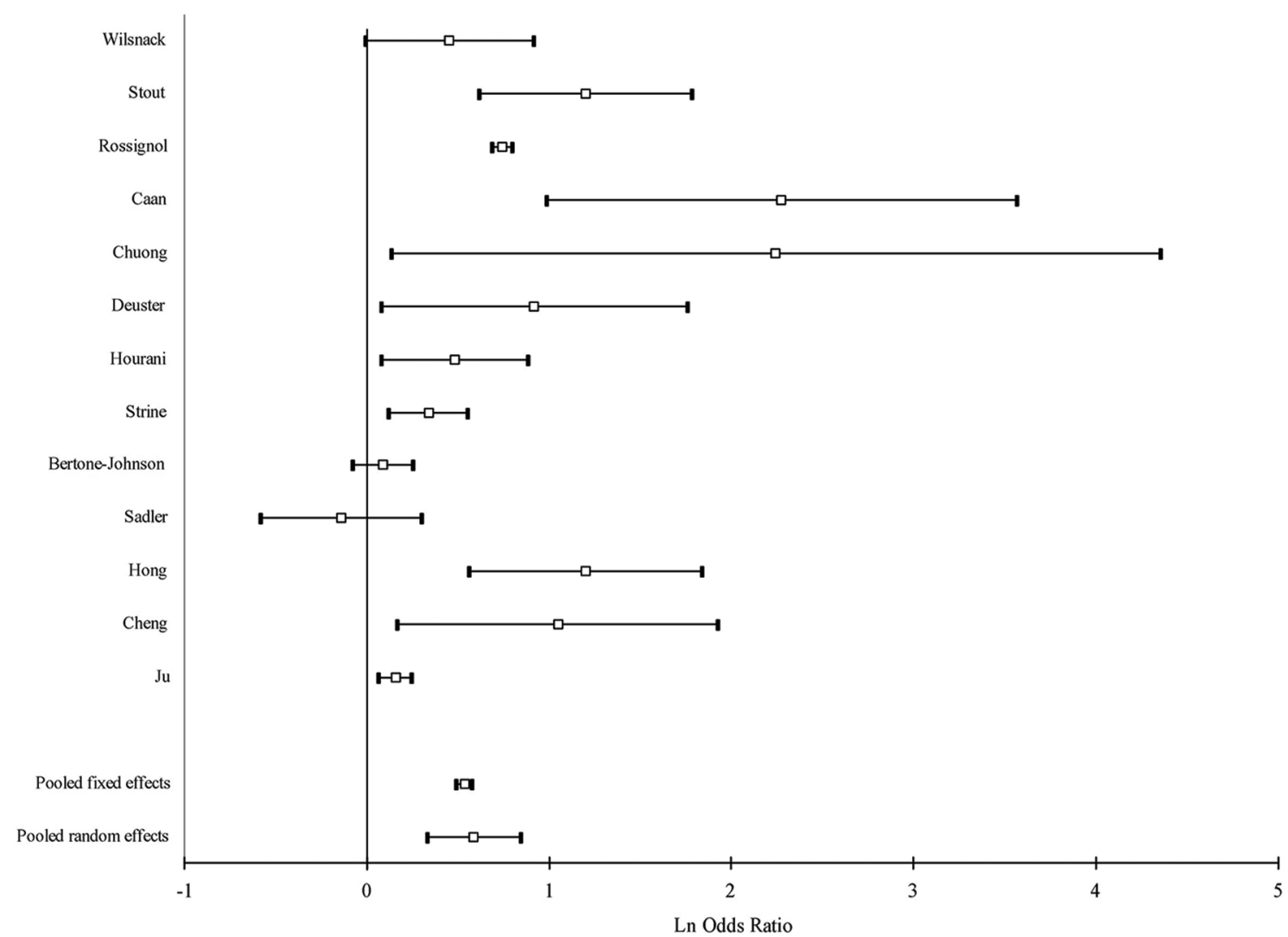

Figure 3 Forest plot of study-specific and pooled OR of alcohol drinking and premenstrual syndrome: heavy drinking. 
Open Access

Table 2 Pooled OR and 95\% (Cl) of premenstrual syndrome and any intake of alcohol

\begin{tabular}{|c|c|c|c|c|c|}
\hline & $\begin{array}{l}\text { Number of } \\
\text { studies }\end{array}$ & $\begin{array}{l}\text { OR }(95 \% \text { Cl) Fixed } \\
\text { effects }\end{array}$ & $\begin{array}{l}\text { OR }(95 \% \mathrm{Cl}) \text { Random } \\
\text { effects }\end{array}$ & $\mathbf{R} \mathbf{i}^{*}$ & $\begin{array}{l}Q \text { test } \mathbf{P} \\
\text { values }\end{array}$ \\
\hline All studies & 19 & 1.31 (1.28 to 1.35$)$ & 1.45 (1.17 to 1.79$)$ & 0.98 & 0.0001 \\
\hline Case-control studies & 7 & 1.27 (1.14 to 1.41$)$ & 1.66 (1.04 to 2.64$)$ & 0.93 & 0.0001 \\
\hline Cross-sectional studies & 11 & 1.67 (1.60 to 1.74$)$ & 1.40 (1.00 to 1.94$)$ & 0.98 & 0.0001 \\
\hline Direct calculations & 17 & 1.31 (1.28 to 1.35$)$ & 1.51 (1.22 to 1.88$)$ & 0.98 & 0.0001 \\
\hline Quality score $\geq 3$ & 10 & 1.11 (1.07 to 1.14$)$ & 1.22 (1.05 to 1.42$)$ & 0.90 & 0.0003 \\
\hline Quality score <3 & 9 & 1.73 (1.66 to 1.80$)$ & 1.50 (1.03 to 2.20$)$ & 0.98 & 0.0001 \\
\hline Full adjustment & 7 & 1.10 (1.07 to 1.14$)$ & 1.18 (1.01 to 1.38$)$ & 0.90 & 0.005 \\
\hline Incomplete adjustment & 12 & 1.70 (1.63 to 1.77$)$ & 1.47 (1.07 to 2.03 ) & 0.98 & 0.0001 \\
\hline Validated exposure & 11 & 1.09 (1.05 to 1.12$)$ & 1.09 (0.99 to 1.20$)$ & 0.77 & 0.006 \\
\hline Non validated exposure & 8 & 2.06 (1.96 to 2.16$)$ & 1.91 (1.40 to 2.62 ) & 0.96 & 0.0001 \\
\hline Validated diagnosis & 12 & 1.85 (1.77 to 1.94$)$ & 1.38 (0.99 to 1.92$)$ & 0.97 & 0.0001 \\
\hline Non validated diagnosis & 7 & $1.10(1.07$ to 1.14$)$ & 1.38 (1.16 to 1.65$)$ & 0.95 & 0.0001 \\
\hline High response rate & 5 & 1.16 (1.05 to 1.28$)$ & 1.36 (0.99 to 1.88$)$ & 0.86 & 0.003 \\
\hline Low response rate & 14 & 1.32 (1.29 to 1.36$)$ & 1.46 (1.13 to 1.89$)$ & 0.98 & 0.0001 \\
\hline Defined target population & 12 & 1.10 (1.07 to 1.13$)$ & 1.20 (1.07 to 1.36$)$ & 0.86 & 0.0001 \\
\hline Undefined target population & 7 & 2.05 (1.95 to 2.15$)$ & 1.65 (1.02 to 2.67$)$ & 0.99 & 0.0001 \\
\hline US studies & 12 & 1.63 (1.57 to 1.70$)$ & 1.56 (1.17 to 2.08$)$ & 0.98 & 0.0001 \\
\hline Rest of the world & 7 & 1.10 (1.06 to 1.14$)$ & 1.24 (0.89 to 1.72$)$ & 0.98 & 0.0001 \\
\hline
\end{tabular}

*Proportion of total variance due to between-study variance.

Table 3 Pooled OR (OR) and 95\% (Cl) of premenstrual syndrome and high intake of alcohol

\begin{tabular}{llllll}
\hline & $\begin{array}{l}\text { Number of } \\
\text { studies }\end{array}$ & $\begin{array}{l}\text { OR (95\% Cl) Fixed } \\
\text { effects }\end{array}$ & $\begin{array}{l}\text { OR (95\% Cl) Random } \\
\text { effects }\end{array}$ & $\begin{array}{l}\text { Q test P } \\
\text { values }\end{array}$ \\
\hline All studies & 13 & $1.71(1.63$ to 1.78$)$ & $1.79(1.39$ to 2.32$)$ & 0.96 & 0.0001 \\
\hline Case-control studies & 5 & $1.27(1.10$ to 1.47$)$ & $2.48(1.30$ to 4.76$)$ & 0.93 & 0.0001 \\
\hline Cross-sectional studies & 7 & $2.02(1.91$ to 2.12$)$ & $1.76(1.32$ to 2.36$)$ & 0.95 & 0.0001 \\
\hline Direct calculations & 12 & $1.91(1.82$ to 2.01$)$ & $1.90(1.45$ to 2.49$)$ & 0.95 & 0.0001 \\
\hline Quality score $\geq 3$ & 8 & $1.20(1.11$ to 1.29$)$ & $1.41(1.14$ to 1.74$)$ & 0.81 & 0.001 \\
\hline Quality score $<3$ & 5 & $2.05(1.95$ to 2.16$)$ & $2.33(1.60$ to 3.41$)$ & 0.96 & 0.0001 \\
\hline Full adjustment & 6 & $1.17(1.08$ to 1.26$)$ & $1.23(1.03$ to 1.48$)$ & 0.72 & 0.03 \\
\hline Incomplete adjustment & 7 & $2.05(1.95$ to 2.16$)$ & $2.25(1.66$ to 3.05$)$ & 0.95 & 0.0001 \\
\hline Validated exposure & 7 & $1.18(1.09$ to 1.27$)$ & $1.32(1.06$ to 1.64$)$ & 0.81 & 0.003 \\
\hline Non validated exposure & 6 & $2.06(1.95$ to 2.17$)$ & $2.25(1.66$ to 3.06$)$ & 0.95 & 0.0004 \\
\hline Validated diagnosis & 7 & $1.95(1.85$ to 2.06$)$ & $1.98(1.31$ to 3.00$)$ & 0.98 & 0.0001 \\
\hline Non validated diagnosis & 6 & $1.26(1.16$ to 1.36$)$ & $1.58(1.22$ to 2.05$)$ & 0.86 & 0.001 \\
\hline High response rate & 4 & $1.23(1.06$ to 1.42$)$ & $1.84(1.07$ to 3.17) & 0.91 & 0.001 \\
\hline Low response rate & 9 & $1.76(1.68$ to 1.84$)$ & $1.80(1.32$ to 2.47$)$ & 0.97 & 0.0001 \\
\hline Defined target population & 8 & $1.23(1.15$ to 1.32$)$ & $1.45(1.21$ to 1.75$)$ & 0.78 & 0.001 \\
\hline Undefined target population & 5 & $2.09(1.98$ to 2.21$)$ & $2.49(1.36$ to 4.58$)$ & 0.99 & 0.0001 \\
\hline US studies & 9 & $1.92(1.83$ to 2.02$)$ & $1.91(1.41$ to 2.59$)$ & 0.96 & 0.0001 \\
\hline Rest of the world & 4 & $1.19(1.09$ to 1.30) & $1.58(0.95$ to 2.63$)$ & 0.96 & 0.001 \\
\hline
\end{tabular}

${ }^{*}$ Proportion of total variance due to between-study variance. 


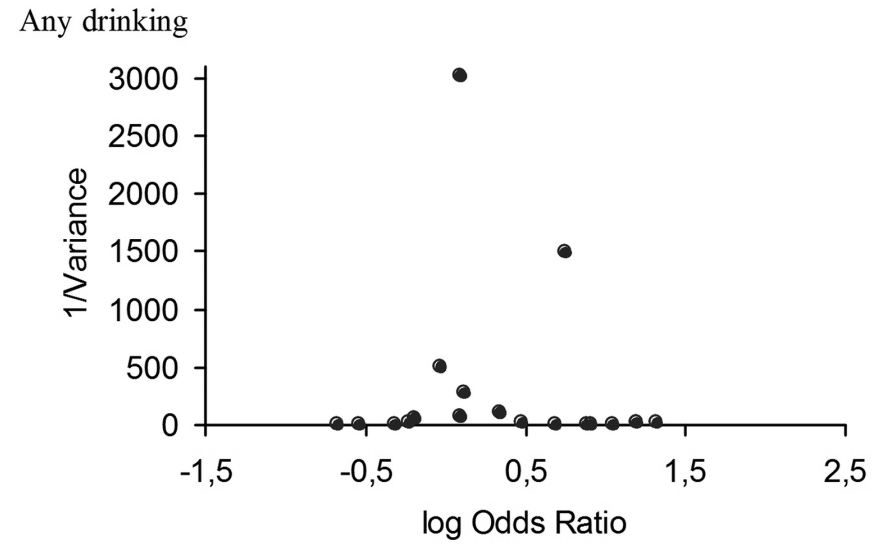

Heavy drinking

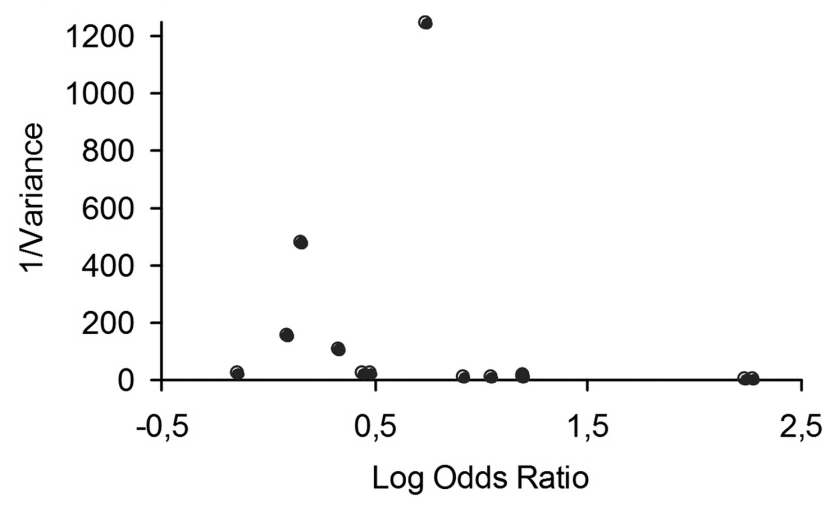

Figure 4 Funnel plot of log OR versus SE of log OR of alcohol drinking and premenstrual syndrome.

causal explanation of the relation between alcohol intake and PMS.

These findings are important given that the worldwide prevalence of alcohol drinking among women is not negligible. Worldwide, the proportion of current female drinkers is $28.9 \%$, while that of heavy female drinkers is $5.7 \%$. In Europe and America these figures are much higher and reach $59.9 \%$ for current drinking and $12.6 \%$ for heavy drinking in Europe. ${ }^{8}$ Based on the figures above and on our results we estimate that $11 \%$ of the PMS cases may be associated to alcohol intake worldwide and $21 \%$ in Europe. ${ }^{55}$ Furthermore, heavy drinking may be associated with $4 \%$ of the PMS cases in the world and over $9 \%$ in Europe. If this association is of causal nature, eliminating heavy drinking in women would then prevent one in every twelve cases of PMS in Europe.

Alcohol use may plausibly increase the risk of PMS by altering levels of sex steroid hormones and gonadotropin during the menstrual cycle. PMS was previously found to be linked to fluctuations of these sex hormones during the cycle. ${ }^{1256}$ Furthermore, alcohol intake may increase the risk of PMS through its effect on serotonin and gamma-amino butyric acid (GABA) activity. On the one hand, women who present alterations in the serotonin and GABA systems may be more sensitive to alcohol. On the other hand it is known that the activity of both serotonin and GABA is altered among subjects with PMS. ${ }^{12}$ In fact, selective serotonin reuptake inhibitors (SSRIs) as well as the GABA-ergic anxiolytic alprazolam may represent effective treatments in PMS cases. ${ }^{56} 57$

The relatively large number of studies conducted and the consistency of the results across study designs and settings provide substantial epidemiological evidence that alcohol drinking may be associated with an increase in the risk of PMS. However, non-causal explanations of the relation should be carefully evaluated.

First, publication bias is a highly unlikely explanation for our results, as the association between alcohol drinking and PMS remained strong even after extremely conservative assumptions regarding the number, size, and findings of studies potentially conducted and not included in our meta-analysis. Also, the findings of the asymmetry tests of the funnel plot as well as those of the trim-and-fill method did not alter our results.

Second, residual confounding (confounding from unknown variables that is not eliminated by adjustment) may have introduced bias as in any meta-analysis of observational studies. It is remarkable that only one-third of the studies included in this meta-analysis considered tobacco smoking in their adjustment in spite of the potential for confounding of this factor. ${ }^{12}$ In our meta-analysis, restricting our analysis to studies that adjusted for potential confounders, including tobacco smoking, did not introduce any substantial modification in the estimate corresponding to any intake of alcohol. The estimate corresponding to heavy intake decreased substantially after restriction to studies with complete adjustment but still shows a $38 \%$ increase in the risk. Furthermore, other confounders that were not measured in the studies of this meta-analysis could explain our results. Recently, some genetic polymorphisms, such as those of the ESR1 gene and those associated to the serotonin $1 \mathrm{~A}$ receptor have been implicated in the occurrence of PMS. ${ }^{559}$ Such genetic factors could theoretically play a role of confounders and explain the results of this meta-analysis concerning alcohol drinking. However, this hypothesis is highly unlikely to be true. First, to act as a confounder, a genetic factor must be related to PMS on the one hand and to alcohol drinking on the other hand. No such factor has been described so far. Second, even if this hypothetical factor could double the risk of PMS among subjects exposed to it (OR confounderdisease $=2$ ) and, simultaneously, this factor happened to be twice as prevalent among alcohol drinkers than among non-drinkers (OR confounder-exposure $=2$ ), the adjusted OR of the relation between any alcohol drinking and PMS would still be 1.21 and that of the relation between heavy drinking and PMS would still be 1.51 (assuming one-third of people are exposed to this unknown factor).$^{60}$ The existence of an unknown factor so strongly related to alcohol intake and to PMS is highly improbable.

Third, measurement error and misclassification of alcohol intake is likely to occur since women may understate their intake of alcohol as many societies hold more negative attitudes towards women's alcohol drinking than men's drinking. ${ }^{8}$ However, this misclassification is 
probably non differential regarding PMS, that is, women with PMS do not underestimate their drinking habits in a different fashion from women who do not suffer PMS. In this case, the bias introduced is then towards the null value. The true OR is then even higher than the one we report in our meta-analysis. Similarly, misclassification of the outcome is also possible (ie, women with PMS who are diagnosed as non-cases, and conversely non-diseased women who are erroneously diagnosed as PMS cases). As previously, this possible misclassification is unlikely to occur differently in women who consume alcohol and in those women who do not. The bias introduced, if any, is towards the null value.

Fourth, given that a substantial proportion of the studies included in this meta-analysis used a cross-sectional design, a reverse causation process, in which PMS-affected women use alcohol to mitigate the effect of this syndrome, could introduce what is known as protopathic bias and thus, explain the results observed. Although in theory this hypothesis should be rejected due to the fact that the pooled estimates for both categories of drinking are higher for case-control studies than for cross-sectional studies, it should be noted that, in several case-control studies included in this meta-analysis, the assessment of alcohol intake was probably concomitant to the assessment of PMS. This hypothesis remains then plausible.

Furthermore, in our subgroup analyses, we were unable to identify any factors that accounted for study heterogeneity. This situation is extremely frequent and for meta-analysis experts, heterogeneity should be viewed more as the rule rather than the exception. ${ }^{61}$ As recommended by experts when heterogeneity is present, in order to deal with this issue, we focused our interpretation on the random effects estimates that are, in general, more conservative. ${ }^{62}$

Our meta-analysis shows that alcohol intake is moderately associated with PMS risk. The consistency of the results and the existence of a plausible biologic mechanism strengthen our conclusions. Future studies should minimise measurement error in the exposure by using validated questionnaires. These studies should avoid cross-sectional designs and focus on determining whether there is a threshold of alcohol intake under which the harmful effect on PMS is non-existent.

Acknowledgements The authors would like to thank Sharon Willsnack and Jeff Kiesner for providing unpublished specific data. All authors approved the final version of the article. All authors agree to be accountable for all aspects of the work in ensuring that questions related to the accuracy or integrity of any part of the work are appropriately investigated and resolved. All authors have completed the Unified Competing Interest form (available on request from the corresponding author) and declare: no support from any organisation for the submitted work; no financial relationships with any organisations that might have an interest in the submitted work in the previous three years, no other relationships or activities that could appear to have influenced the submitted work. The corresponding author affirms that this manuscript is an honest, accurate, and transparent account of the study being reported; that no important aspects of the study have been omitted; and that any discrepancies from the study as planned have been explained.

Contributors MdM performed the computerized systematic search, literature revision, risk of bias assessment, meta-analysis and redaction of the manuscript, figures and tables. JS assessed the risk of bias and revised the manuscript. HI provided unpublished data and participated in the redaction of the manuscript. BT did the complementary searches, assessment of the publication bias and revision of the final manuscript, figures and tables. He acts as a guarantor of the study.

Funding This research received no specific grant from any funding agency in the public, commercial or not-for-profit sectors.

Competing interests None declared.

Patient consent Not required.

Provenance and peer review Not commissioned; externally peer reviewed.

Data sharing statement No additional data available besides those available in the tables and supplementary files of this manuscript. The database ready to be analyzed can be obtained from the corresponding author upon request.

Open Access This is an Open Access article distributed in accordance with the Creative Commons Attribution Non Commercial (CC BY-NC 4.0) license, which permits others to distribute, remix, adapt, build upon this work non-commercially, and license their derivative works on different terms, provided the original work is properly cited and the use is non-commercial. See: http://creativecommons.org/ licenses/by-nc/4.0/

(c) Article author(s) (or their employer(s) unless otherwise stated in the text of the article) 2018. All rights reserved. No commercial use is permitted unless otherwise expressly granted.

\section{REFERENCES}

1. O'Brien PM, Bäckström T, Brown C, et al. Towards a consensus on diagnostic criteria, measurement and trial design of the premenstrual disorders: the ISPMD Montreal consensus. Arch Womens Ment Health 2011;14:13-21.

2. Rapkin AJ, Winer SA. Premenstrual syndrome and premenstrual dysphoric disorder: quality of life and burden of illness. Expert Rev Pharmacoecon Outcomes Res 2009;9:157-70.

3. Sternfeld B, Swindle R, Chawla A, et al. Severity of premenstrual symptoms in a health maintenance organization population. Obstet Gynecol 2002;99:1014-24.

4. Direkvand-Moghadam A, Sayehmiri K, Delpisheh A, et al. Epidemiology of premenstrual syndrome (PMS)-a systematic review and meta-analysis study. J Clin Diagn Res 2014;8:106-9.

5. Borenstein JE, Dean BB, Endicott J, et al. Health and economic impact of the premenstrual syndrome. J Reprod Med 2003;48:515-24.

6. Futterman LA, Rapkin AJ. Diagnosis of premenstrual disorders. $J$ Reprod Med 2006;51:349-58.

7. Bertone-Johnson ER, Whitcomb BW, Rich-Edwards JW, et al. Premenstrual syndrome and subsequent risk of hypertension in a prospective study. Am J Epidemiol 2015;182:1000-9.

8. World Health Organization. Global status report on alcohol and health 2014. 2014 http://apps.who.int/iris/bitstream/10665/112736/1/ 9789240692763_eng.pdf (accessed 11 Dec 2017).

9. Deuster PA, Adera T, South-Paul J. Biological, social, and behavioral factors associated with premenstrual syndrome. Arch Fam Med 1999;8:122-8.

10. Strine TW, Chapman DP, Ahluwalia IB. Menstrual-related problems and psychological distress among women in the United States. $J$ Womens Health 2005;14:316-23.

11. Skrzypulec-Plinta V, Drosdzol A, Nowosielski K, et al. The complexity of premenstrual dysphoric disorder--risk factors in the population of Polish women. Reprod Biol Endocrinol 2010;8:141.

12. Bertone-Johnson ER, Hankinson SE, Johnson SR, et al. Timing of alcohol use and the incidence of premenstrual syndrome and probable premenstrual dysphoric disorder. J Womens Health 2009;18:1945-53.

13. Gold EB, Bair $Y$, Block $G$, et al. Diet and lifestyle factors associated with premenstrual symptoms in a racially diverse community sample: Study of Women's Health Across the Nation (SWAN). J Womens Health 2007;16:641-56.

14. Sadler C, Smith H, Hammond J, et al. Lifestyle factors, hormonal contraception, and premenstrual symptoms: the United Kingdom Southampton Women's Survey. J Womens Health 2010;19:391-6.

15. Wilsnack SC, Klassen AD, Wilsnack RW. Drinking and reproductive dysfunction among women in a 1981 national survey. Alcohol Clin Exp Res 1984;8:451-8.

16. Kiesner J. Affective response to the menstrual cycle as a predictor of self-reported affective response to alcohol and alcohol use. Arch Womens Ment Health 2012;15:423-32. 
17. Wells G, Shea B, O'Connell D, et al. The Newcastle-Ottawa Scale (NOS) for assessing the quality of nonrandomised studies in metaanalyses. Ottawa Health Research Institute 2012 (accessed 11 Dec 2017).

18. Rothman KJ, Greenland S, Lash TL. Measure of effect and measures of association. In: Modern Epidemiology. 3rd Edn. Philadelphia: Lippincott, Williams and Wilkins, 2008.

19. Griffin ML, Mello NK, Mendelson JH, et al. Alcohol use across the menstrual cycle among marihuana users. Alcohol 1987;4:457-62.

20. Nillni YI, Rohan KJ, Bernstein A, et al. Premenstrual distress predicts panic-relevant responding to a $\mathrm{CO} 2$ challenge among young adult females. J Anxiety Disord 2010;24:416-22.

21. Bryant M, Truesdale KP, Dye L. Modest changes in dietary intake across the menstrual cycle: implications for food intake research. $\mathrm{Br}$ J Nutr 2006;96:888-94.

22. Reed SC, Levin FR, Evans SM. Changes in mood, cognitive performance and appetite in the late luteal and follicular phases of the menstrual cycle in women with and without PMDD (premenstrual dysphoric disorder). Horm Behav 2008;54:185-93.

23. Borenstein M, Hedges LV, Higgins JPT. Converting among effect sizes. In: Borenstein M, Hedges LV, Higgins JPT, Rothstein HR, et al. Introduction to Meta-Analysis. Chichester, UK: John Wiley \& Sons, 2009:45-9.

24. Takkouche B, Cadarso-Suárez C, Spiegelman D. Evaluation of old and new tests of heterogeneity in epidemiologic meta-analysis. Am J Epidemiol 1999;150:206-15.

25. Egger M, Davey Smith G, Schneider M, et al. Bias in meta-analysis detected by a simple, graphical test. BMJ 1997;315:629-34.

26. Costa-Bouzas J, Takkouche B, Cadarso-Suárez C, et al. HEPIMA: software for the identification of heterogeneity in meta-analysis. Comput Methods Programs Biomed 2001;64:101-7.

27. Stout AL, Steege JF, Blazer DG, et al. Comparison of lifetime psychiatric diagnoses in premenstrual syndrome clinic and community samples. J Nerv Ment Dis 1986;174:517-22.

28. Rossignol AM, Bonnlander H. Prevalence and severity of the premenstrual syndrome. Effects of foods and beverages that are sweet or high in sugar content. J Reprod Med 1991;36:131-6.

29. Caan B, Duncan D, Hiatt R, et al. Association between alcoholic and caffeinated beverages and premenstrual syndrome. J Reprod Med 1993;38:630-6.

30. Chuong CJ, Burgos DM. Medical history in women with premenstrual syndrome. J Psychosom Obstet Gynaecol 1995;16:21-7.

31. Hourani LL, Yuan H, Bray RM. Psychosocial and lifestyle correlates of premenstrual symptoms among military women. $J$ Womens Health 2004;13:812-21.

32. Forrester-Knauss C, Zemp Stutz E, Weiss C, et al. The interrelation between premenstrual syndrome and major depression: results from a population-based sample. BMC Public Health 2011;11:795.

33. Pinar G, Colak M, Oksuz E. Premenstrual syndrome in Turkish college students and its effects on life quality. Sex Reprod Healthc 2011;2:21-7.

34. Hong JP, Park S, Wang HR, et al. Prevalence, correlates, comorbidities, and suicidal tendencies of premenstrual dysphoric disorder in a nationwide sample of Korean women. Soc Psychiatry Psychiatr Epidemiol 2012;47:1937-45.

35. Cheng SH, Shih CC, Yang YK, et al. Factors associated with premenstrual syndrome - a survey of new female university students. Kaohsiung J Med Sci 2013;29:100-5.

36. Ju H, Jones M, Mishra GD. Illicit drug use, early age at first use and risk of premenstrual syndrome: A longitudinal study. Drug Alcohol Depend 2015;152:209-17.

37. Kritz-Silverstein D, Wingard DL, Garland FC. The association of behavior and lifestyle factors with menstrual symptoms. J Womens Health Gend Based Med 1999;8:1185-93.

38. Harvey SM, Beckman LJ. Cyclic fluctuation in alcohol consumption among female social drinkers. Alcohol Clin Exp Res 1985;9:465-71.

39. Schechter D, Bachmann GA, Vaitukaitis J, et al. Perimenstrual symptoms: time course of symptom intensity in relation to endocrinologically defined segments of the menstrual cycle. Psychosom Med 1989;51:173-94.
40. McLeod DR, Foster GV, Hoehn-Saric R, et al. Family history of alcoholism in women with generalized anxiety disorder who have premenstrual syndrome: patient reports of premenstrual alcohol consumption and symptoms of anxiety. Alcohol Clin Exp Res 1994;18:664-70.

41. Svikis DS, Miles DR, Haug NA, et al. Premenstrual symptomatology, alcohol consumption, and family history of alcoholism in women with premenstrual syndrome. J Stud Alcohol 2006;67:833-6.

42. Wood C, Larsen L, Williams R. Social and psychological factors in relation to premenstrual tension and menstrual pain. Aust $N Z \mathrm{~J}$ Obstet Gynaecol 1979;19:111-5.

43. Charette L, Tate DL, Wilson A. Alcohol consumption and menstrual distress in women at higher and lower risk for alcoholism. Alcohol Clin Exp Res 1990;14:152-7.

44. Gannon L, Luchetta T, Pardie L, et al. Perimenstrual symptoms: relationships with chronic stress and selected lifestyle variables. Behav Med 1989;15:149-59.

45. Marks JL, Hair CS, Klock SC, et al. Effects of menstrual phase on intake of nicotine, caffeine, and alcohol and nonprescribed drugs in women with late luteal phase dysphoric disorder. J Subst Abuse 1994;6:235-43.

46. Wittchen $\mathrm{H}-\mathrm{U}$, Becker $\mathrm{E}$, Lieb R, et al. Prevalence, incidence and stability of premenstrual dysphoric disorder in the community. Psychol Med 2002;32:119-32.

47. Kim SH, Lee JH. Study on Relation between Premenstrual Syndrome (PMS) and nutritional intake, blood composition of female college students. Korean J Community Nutr 2005;10:603-14.

48. Bertone-Johnson ER, Hankinson SE, Willett WC, et al. Adiposity and the development of premenstrual syndrome. $J$ Womens Health 2010;19:1955-62.

49. Tobin MB, Schmidt PJ, Rubinow DR. Reported alcohol use in women with premenstrual syndrome. Am J Psychiatry 1994;151:1503-4.

50. Christensen AP, Oei TP, Callan VJ. The relationship between premenstrual dysphoria and daily ratings dimensions. J Affect Disord 1989;16:127-32.

51. Mello NK, Mendelson JH, Lex BW. Alcohol use and premenstrual symptoms in social drinkers. Psychopharmacology 1990;101:448-55.

52. Song JE, Chae HJ, Jang WH, et al. The relationship between life style, menstrual attitude and premenstrual syndrome in nursing students. Korean J Women Health Nursing 2013;19:119-28.

53. Perry BL, Miles D, Burruss K, et al. Premenstrual symptomatology and alcohol consumption in college women. J Stud Alcohol 2004;65:464-8.

54. Stroup DF, Berlin JA, Morton SC, et al. Meta-analysis of observational studies in epidemiology: a proposal for reporting Meta-analysis Of Observational Studies in Epidemiology (MOOSE) group. JAMA 2000;283:2008-12.

55. Rothman KJ. Modern epidemiology. Boston: Little, Brown and Co, 1986:39.

56. Halbreich U. The etiology, biology, and evolving pathology of premenstrual syndromes. Psychoneuroendocrinology 2003;28(Suppl 3):55-99.

57. Rapkin A. A review of treatment of premenstrual syndrome and premenstrual dysphoric disorder. Psychoneuroendocrinology 2003;28(Suppl 3):39-53.

58. Pakharenko L. Effect of estrogen receptor gene ESR1 polymorphism on development of premenstrual syndrome. Georgian Med News 2014;235:37-41.

59. Yen JY, Tu HP, Chen CS, et al. The effect of serotonin $1 \mathrm{~A}$ receptor polymorphism on the cognitive function of premenstrual dysphoric disorder. Eur Arch Psychiatry Clin Neurosci 2014;264:729-39.

60. Greenland S. Basic methods for sensitivity analysis of biases. Int J Epidemiol 1996;25:1107-16.

61. Berlin JA. Invited commentary: benefits of heterogeneity in metaanalysis of data from epidemiologic studies. Am J Epidemiol 1995;142:383-7.

62. Higgins JP. Commentary: Heterogeneity in meta-analysis should be expected and appropriately quantified. Int J Epidemiol 2008;37:1158-60. 